\title{
Ras-Related GTP-Binding Protein C
}

National Cancer Institute

\section{Source}

National Cancer Institute. Ras-Related GTP-Binding Protein C. NCI Thesaurus. Code C142217.

Ras-related GT P-binding protein C (399 aa, $\sim 44 \mathrm{kDa}$ ) is encoded by the human RRAGC gene. This protein is involved in the localization of the mammalian target of rapamycin complex 1 (mTORC1). 